OPEN ACCESS

Edited by:

Laura Kehoe,

University of Victoria, Canada

Reviewed by: James Fitzsimons,

The Nature Conservancy, United States

Viorel Dan Popescu,

Ohio University, United States

*Correspondence:

Cassidy C. D'Aloia

cdaloia@unb.ca

tThese authors have contributed equally to this work

Specialty section: This article was submitted to

Conservation,

a section of the journa

Frontiers in Ecology and Evolution

Received: 01 October 2018

Accepted: 28 January 2019

Published: 14 February 2019

Citation:

D'Aloia CC, Naujokaitis-Lewis I, Blackford C, Chu C, Curtis JMR,

Darling E, Guichard F, Leroux SJ,

Martensen AC, Rayfield B,

Sunday JM, Xuereb A and Fortin M-J

(2019) Coupled Networks of

Permanent Protected Areas and

Dynamic Conservation Areas for

Biodiversity Conservation Under Climate Change.

Front. Ecol. Evol. 7:27.

doi: 10.3389/fevo.2019.00027

\section{Coupled Networks of Permanent Protected Areas and Dynamic Conservation Areas for Biodiversity Conservation Under Climate Change}

\author{
Cassidy C. D'Aloia ${ }^{1,2 * t}$, llona Naujokaitis-Lewis ${ }^{3+}$, Christopher Blackford ${ }^{2}$, Cindy Chu ${ }^{4}$, \\ Janelle M. R. Curtis ${ }^{5}$, Emily Darling ${ }^{2,6}$, Frédéric Guichard ${ }^{7}$, Shawn J. Leroux ${ }^{8}$, \\ Alexandre C. Martensen ${ }^{9}$, Bronwyn Rayfield ${ }^{10,11}$, Jennifer M. Sunday ${ }^{7}$, Amanda Xuereb ${ }^{2}$ \\ and Marie-Josée Fortin ${ }^{2}$ \\ 1 Department of Biological Sciences, University of New Brunswick, Saint John, NB, Canada, ${ }^{2}$ Department of Ecology \& \\ Evolutionary Biology, University of Toronto, Toronto, ON, Canada, ${ }^{3}$ National Wildlife Research Centre, Environment and \\ Climate Change Canada, Carleton University, Ottawa, ON, Canada, ${ }^{4}$ Aquatic Research and Monitoring Section, Ontario \\ Ministry of Natural Resources and Forestry, Peterborough, ON, Canada, ${ }^{5}$ Pacific Biological Station, Fisheries and \\ Oceans Canada, Nanaimo, BC, Canada, ${ }^{6}$ Marine Program, Wildlife Conservation Society, Bronx, NY, United States, \\ ${ }^{7}$ Department of Biology, McGill University, Montreal, QC, Canada, ${ }^{8}$ Department of Biology, Memorial University, St. John's, \\ NL, Canada, ${ }^{9}$ Centro de Ciências da Natureza, Federal University of São Carlos, São Carlos, Brazil, ${ }^{10}$ Département des \\ Sciences Naturelles, Institut des Sciences de la Forêt Tempérée, Université du Québec en Outaouais, Ripon, QC, Canada, \\ ${ }^{11}$ Apex Resource Management Solutions Ltd., Ottawa, ON, Canada
}

The complexity of climate change impacts on ecological processes necessitates flexible and adaptive conservation strategies that cross traditional disciplines. Current strategies involving protected areas are predominantly fixed in space, and may on their own be inadequate under climate change. Here, we propose a novel approach to climate adaptation that combines permanent protected areas with temporary conservation areas to create flexible networks. Previous work has tended to consider permanent and dynamic protection as separate actions, but their integration could draw on the strengths of both approaches to improve biodiversity conservation and help manage for ecological uncertainty in the coming decades. As there are often time lags in the establishment of new permanent protected areas, the inclusion of dynamic conservation areas within permanent networks could provide critical transient protection to mitigate land-use changes and biodiversity redistributions. This integrated approach may be particularly useful in highly human-modified and fragmented landscapes where areas of conservation value are limited and long-term place-based protection is unfeasible. To determine when such an approach may be feasible, we propose the use of a decision framework. Under certain scenarios, these coupled networks have the potential to increase spatio-temporal network connectivity and help maintain biodiversity and ecological processes under climate change. Implementing these networks would require multidisciplinary scientific evidence, new policies, creative funding solutions, and broader acceptance of a dynamic approach to biodiversity conservation.

Keywords: dynamic management, spatial ecology, protected area, conservation planning, climate change adaptation, temporary conservation 


\section{INTRODUCTION}

In both terrestrial and aquatic environments, anthropogenic climate change has altered ecological processes across all levels of biological organization (Scheffers et al., 2016). Although landuse change, overexploitation, and pollution have been historically important drivers of biodiversity loss, climate change is expected to exert disproportionately negative impacts in the future (Urban et al., 2016). Developing effective cross-disciplinary strategies to conserve biodiversity and ecosystem services that address the multidimensional impacts of climate change remains a major conservation challenge (Knight et al., 2006; Jones et al., 2016).

Ecological systems are inherently dynamic, yet efforts to protect biodiversity have traditionally been fixed in space (i.e., static) (Thomas and Gillingham, 2015). Indeed, the implementation of permanent protected areas (PAs) is static by design. Protected areas can be tailored to address climate change impacts by increasing their size, protecting habitats that are projected to be suitable in the future, or improving landscape connectivity by permanently protecting stepping stones that facilitate climate-driven redistributions (Stein et al., 2013; Tingley et al., 2014). However, these static approaches are often limited in their ability to respond to rapid environmental change, and have elicited a need to integrate spatially dynamic threats into conservation planning (Araújo et al., 2011).

Two major advances relevant to spatially-explicit, climateadaptive conservation have progressed independently. First, there has been a growing interest in dynamic area-based management. Under this approach, areas are temporarily protected from anthropogenic pressures, and later released from formal protection when they are no longer needed. To date, this idea has gained the most traction in marine environments (e.g., Game et al., 2009; Lewison et al., 2015), but it is also applicable to terrestrial and freshwater environments (e.g., Bengtsson et al., 2003; Alagador et al., 2014). Dynamic strategies may be especially useful in fragmented areas with a strong human footprint, such as urban environments, where areas of actual or potential conservation value are spatially limited and temporally variable (Kattwinkel et al., 2011), and for species with certain ecological traits such as migratory behaviors (Hobday et al., 2010). Second, there has been a concerted effort to shift from considering individual permanent PAs to networks of connected PAs (Kininmonth et al., 2010; Gerber et al., 2014). Designing well-connected networks has become a major goal of conservation planning because the exchange of material, individuals, and species between PAs can help maintain diversity and function within the entire network (Daigle et al., 2018). Integrating these two approaches may protect dynamic ecological processes. Some insight can be drawn from largescale connectivity projects (Worboys et al., 2010) and multitenure reserve networks that combine dynamic mechanisms with permanent PA networks (Fitzsimons and Wescott, 2005). Various government agencies have also proposed the use of dynamic conservation areas as part of broader management plans (e.g., temporal protection for whale calving grounds in Victoria, Australia; Environment Conservation Council, 2000), but there has not been substantial implementation.
To facilitate a broader uptake of dynamic conservation, we draw upon these advances to develop an integrated strategy that focuses on the potential for dynamic conservation areas to augment traditional networks of permanent PAs. We define dynamic conservation areas as areas that are temporarily protected. They would be specifically designed to protect the increasingly dynamic nature of landscapes, riverscapes, and seascapes (hereafter, collectively referred to as "landscapes") as well as population, community, and ecosystemlevel processes (e.g., dispersal, migration, and nutrient cycling). While static network approaches and dynamic management actions have been proposed as independent climate change adaptation strategies (McLeod et al., 2009; Fuller et al., 2010; Bull et al., 2013; Alagador et al., 2014), a conceptual framework for the design of coupled networks that integrate both permanent PAs and dynamic conservation areas is lacking. We surmise that these coupled networks stand to bolster metapopulation, metacommunity, and meta-ecosystem persistence across landscapes. Below, we outline the benefits and limitations of implementing spatially and temporally fixed (i.e., permanent) or spatially and/or temporally transient (i.e., dynamic) protection in response to climate change, and then highlight the key advantages of coupling permanent PAs and dynamic conservation areas into integrated networks. Finally, we present a decision framework to assist in navigating the complex decision space and trade-offs associated with integrating dynamic conservation into the broader network.

\section{SPATIAL ECOLOGICAL THEORY TO INFORM CLIMATE-SMART CONSERVATION}

Networks of permanent PAs have been widely advocated to protect metapopulations (Kininmonth et al., 2010), metacommunities (Gerber et al., 2014), and meta-ecosystems (Spiecker et al., 2016). PA networks can be designed using network theory, where each PA is a node, and material, energy, or species' probabilities to move between nodes constitute links. Collectively, these links drive the dynamics of nodes and the response of whole networks to environmental changes (Guichard et al., 2004). Connectivity among PAs can fluctuate along with changes in environmental and climatic conditions (Watson et al., 2012), and losses in connectivity can result in the rapid decay of diversity and ecosystem function (Thompson et al., 2016). Hence, the role of connectivity for the stability and productivity of ecological systems depends on the distribution of movement rates and distances across the network and among interacting species. In general, permanent PA networks can mitigate some climate change effects and benefit biodiversity by providing high quality habitat for species, communities, and ecosystems as they cope with climate stress (Thomas and Gillingham, 2015).

Even when permanent PAs are well-designed for current conditions, they are not immune to future abiotic and biotic changes (Hannah et al., 2007; Gerber et al., 2014). For example, species that track gradual climatic shifts may move out of protected areas before new permanent PAs can be established 
in appropriate locations (Araújo et al., 2011; Poloczanska et al., 2013). These gradual shifts are compounded by the uncertainty of extreme climate events. As one example, recurrent coral bleaching in 1998, 2002, and 2016 across the Great Barrier Reef highlights the sobering reality that even the best-managed PAs are subject to the influence of extreme climate events (Hughes et al., 2017). In a changing climate, it is clear that we need additional conservation tools and strategies to safeguard local and global biodiversity (Fordham et al., 2013).

Recognizing some of the limitations of static PAs in the context of global change, dynamic conservation areas represent a complementary approach. By matching dynamic management to dynamic ecological processes, specific areas and/or periods could be strategically targeted for temporary protection (Cumming et al., 1996; Rayfield et al., 2008; Game et al., 2009). Within the context of our proposed integrated network framework, dynamic conservation areas differ from other temporary actions, such as sequential scheduling of temporary conservation areas (Alagador et al., 2014) and biodiversity offsets (Bull et al., 2013), as their primary goal is to improve network connectivity in the face of climate change. By using new technologies that facilitate realtime data collection, these dynamic areas could also be used to track changes in suitable habitat over space and time that are driven by climate change and other anthropogenic stressors. In this way, dynamic conservation areas can confer protection that is either (1) temporary in time, by periodically protecting the same place to target a dynamic ecological process (e.g., a species' migration pathway), or (2) temporary in both time and space, by protecting different places over time to account for environmental variability.

\section{A CLOSER LOOK AT DYNAMIC CONSERVATION AREAS}

\section{Dynamic Conservation Case Studies}

Case studies across ecological realms have demonstrated that, under certain conditions, dynamic protection can have positive impacts on wildlife and ecosystems. Mobile species, including migratory, nomadic, and irruptive species, represent the clearest beneficiaries of dynamic protection (Runge et al., 2014). For example, The Nature Conservancy is leading collaborative efforts to establish "pop-up wetlands" in California based on predictive models of bird occurrence and surface water availability (Reynolds et al., 2017; Golet et al., 2018). These temporary wetlands facilitate waterbird seasonal migrations through intensive agricultural mosaics, especially during droughts.

In another example, a framework to identify critical habitat for the endangered Peary caribou (Rangifer tarandus pearyi) recognizes the need for dynamic management of migratory corridors to reflect seasonal space use (Johnson et al., 2017). Climate-driven loss of snow and ice habitat is a primary threat to Peary caribou persistence. Using high-resolution climate data, dynamic modeling approaches can recommend the best locations for temporary protection of movement corridors at fine temporal scales. Potential locations for dynamic protection can be updated as new information, such as climate, weather or biological data, becomes available in real or near-real time (Lewison et al., 2015; Tommasi et al., 2017). At a broader temporal scale, forest management plans are increasingly recognizing the need to plan for future wildlife habitat connectivity under climate change. One dynamic strategy is to concentrate harvesting areas and then rotate these areas over time to minimize disturbance footprints and promote habitat connectivity for focal species (Armstrong et al., 2012). Collectively, these examples highlight the flexible and adaptive nature of dynamic actions in relation to species and ecosystem responses, changing environments, and shifting exploitation patterns.

\section{Considerations for Implementing Dynamic Conservation Areas}

While flexibility and responsiveness are some of the strengths of a dynamic approach to conservation, the decision to implement these actions will require balancing expected long-term gains with a number of considerations including logistics, feasibility, and uncertainties associated with future climate change and biodiversity responses to these changes (Moilanen et al., 2014). In part, the success of dynamic conservation areas depends upon whether scientific evidence can support their strategic and timely placement on the landscape. A lack of fundamental biological data at the species level (e.g., dispersal capacity, physiology, and demography) and higher (e.g., interspecific interactions in transient communities) represents a major challenge to models that aim to forecast biodiversity responses to climate change (Beckage et al., 2011; Urban et al., 2016). In response to imperfect data availability, one argument has been to invest more heavily in basic research to improve forecasting models (Urban et al., 2016). Others have argued that a more appropriate tactic is "scenario planning" (Schindler and Hilborn, 2015), which involves preparing for a range of potential outcomes via flexible policy responses. We believe that dynamic conservation areas align with both viewpoints because their purpose is to provide flexible place-based protection.

Moreover, the case studies presented above demonstrate that flexible conservation responses to short-term forecasting and/or near real-time observations can be implemented at fine spatial and temporal scales when data and associated technologies allow ecologists to accurately measure change. Advances in animal telemetry (Hussey et al., 2015; Kays et al., 2015) coupled with remote sensing of the environment (Stapleton et al., 2014) are increasing capacity to build predictive models of environmental change and species' responses to these changes at spatio-temporal scales relevant to resource managers (e.g., season, landscape). The emergence of open science and online repositories (e.g., movebank.org) provide the means to validate model predictions (Mouquet et al., 2015), potentially supporting conservation actions such as the quick implementation of dynamic PAs.

As with all new initiatives, dynamic conservation raises new challenges, but it is our view that current scientific challenges should not stymy the development of ideas for creative biodiversity conservation. Moving forward, we anticipate that the greatest benefits of dynamic conservation areas will occur when 
they are intentionally planned and proactively integrated into existing networks of permanent PAs, rather than only reactive, opportunistic, or isolated conservation measures.

\section{COUPLING PERMANENT PAs WITH DYNAMIC CONSERVATION AREAS INTO AN EFFECTIVE NETWORK}

We argue that an integrated strategy that includes both permanent and dynamic components may be well-suited to protect biodiversity given the anticipated challenges and uncertainty associated with climate change. Through the lens of network theory, we propose that both permanent PAs and dynamic conservation areas can serve as nodes (Figure 1). Permanent PAs (fixed nodes) can be thought of as the pillars of this strategy, while dynamic conservation areas (temporary nodes) are strategically implemented and removed (if not needed in the future) to accomplish specific objectives that are not achieved by permanent PAs. These two types of nodes can be connected by dynamic links, which may represent either physical connections (e.g., corridors), or the probability of exchange between nodes (e.g., the movement of energy or nutrients, or the dispersal of individuals). An integrated approach could maintain network connectivity across space and time, which, in turn, will play an important role in responding to climate-induced changes in habitats and dynamic biological processes such as seasonal migrations. This approach aligns with a broader call to incorporate dynamic processes and threats into systematic conservation planning (SCP) (Pressey et al., 2007). SCP software, such as Marxan Connect, could be used as a decision support tool to determine when dynamic conservation areas would help achieve project-specific conservation targets, e.g., by enhancing network connectivity (Daigle et al., 2018).

In general, the placement of permanent and dynamic nodes within these coupled networks should be guided by the different roles that they serve (Figure 1). Ideally, permanent nodes are in locations that are robust to future climate change, allowing them to maintain their long-term conservation goals (Keppel et al., 2015). Indeed, many countries have already implemented a substantial number of permanent terrestrial PAs (but note coverage lags in aquatic environments), and a large body of literature provides guidance on the expansion of permanent PAs and the role of connectivity in designing PA networks (e.g., Stein et al., 2013; Gerber et al., 2014; Tingley et al., 2014). Yet, there are some areas, particularly fragmented areas with a large human footprint, where implementing new permanent PAs simply may not be possible. In such cases, dynamic conservation areas could be implemented to provide critical stepping stone habitat to track species, communities, and ecosystems as their distributions change (Figure 1A). Stepping stones are expected to be especially important in maintaining spatiotemporal network connectivity in dynamic landscapes that are changing over time due to climate change or other humaninduced disturbances (Martensen et al., 2017). These dynamic areas could also protect peripheral populations or ecosystems as biodiversity is redistributed outside of network bounds (Figure 1B). For example, temporary place-based protection at expanding range margins could help new populations establish, and may eventually protect novel genotypes if local adaptation occurs (Hill et al., 2011). Additionally, maintaining links with the rest of the network could prevent peripheral extinctions via genetic rescue (Whiteley et al., 2015). In general, coupling permanent PAs with dynamic conservation areas could produce emergent networks that provide spatial and temporal insurance

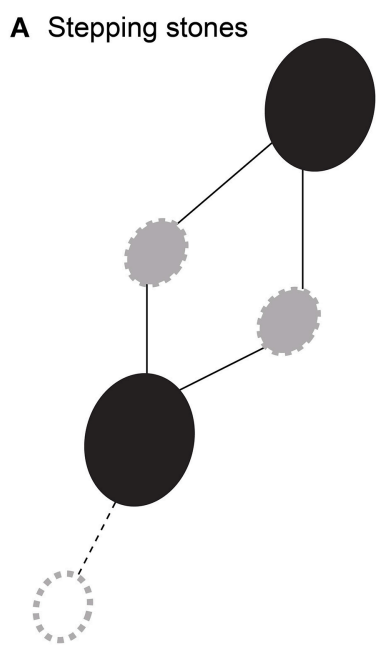

B Peripheral nodes

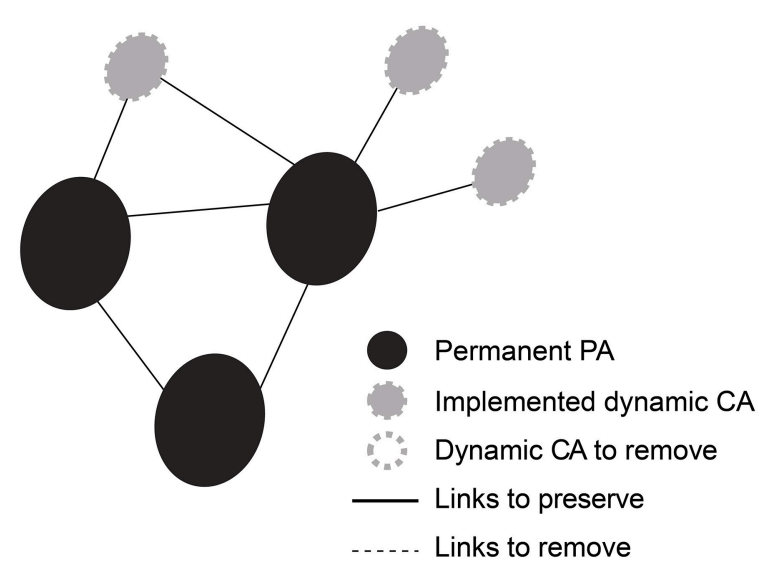

FIGURE 1 | Conceptual diagram illustrating the integration of permanent PAs and dynamic conservation areas (CAs) to strengthen network connectivity. Nodes represent PAs and CAs; links represent either material/organism flow or physical corridors. (A) Dynamic CAs can serve as stepping stones to enhance connectivity, and can be removed when they are no longer needed for conservation objectives; (B) Dynamic CAs can connect peripheral populations or ecosystems to the rest of the network. 
against the known failings of relying exclusively on permanent PA networks, and the limited time horizon of dynamic protection. These networks are scalable across both space and time, and their design should reflect the ecological processes or biological entities they are intended to protect, and the scale-dependent conservation objectives they are intended to meet.

\section{A DECISION FRAMEWORK FOR PUTTING INTEGRATED NETWORKS INTO PRACTICE}

Any decision to implement an integrated spatial network that includes both permanent PAs and dynamic conservation areas will require consideration of relevant ecological, technological, socioeconomic, cultural, and logistical factors. Initially, one must consider whether there is a need for dynamic conservation areas (Figure 2, Part 1). In other words, is there an ecological process that changes over space and/or time that could benefit from temporary protection? In some cases, augmenting static networks with dynamic conservation areas may be necessary to safeguard biodiversity or to maintain or enhance connectivity. Importantly, the ability to implement dynamic protection that buffers against climate change consequences will depend upon reliable biological data, predictive models that integrate multiple sources of uncertainties, and improved climate forecasting.

The next group of decisions must assess the spatial configuration of the existing network in the context of the surrounding landscape and the pace of ecological change (Figure 2, Part 2). Previous work has shown that the degree to which dynamic conservation areas improve the ability of permanent PAs to safeguard biodiversity hinges upon the existence of high quality habitat elsewhere in the landscape

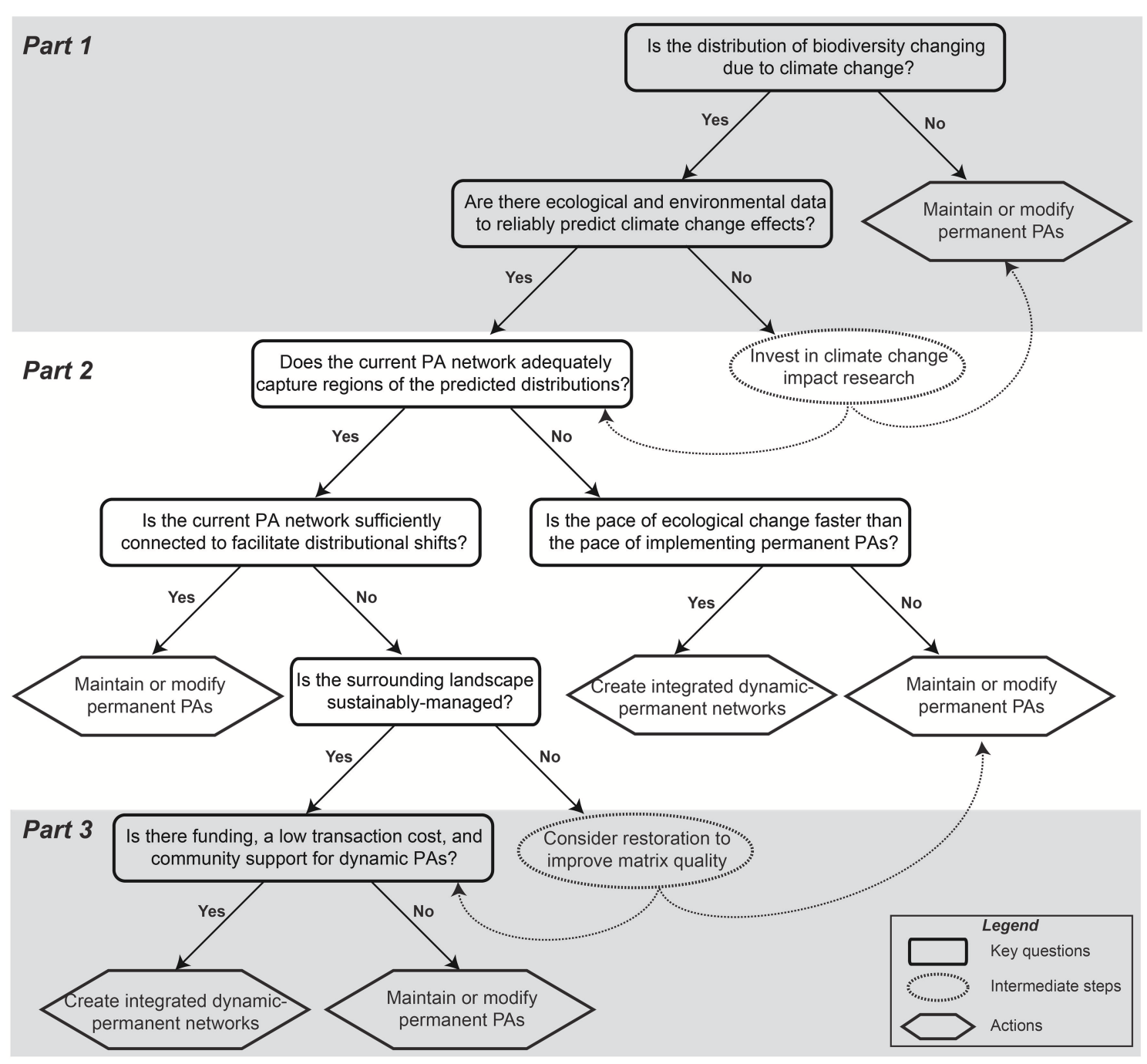

FIGURE 2 | A decision tree for the implementation of strictly permanent PA networks vs. integrated dynamic-permanent networks. As an example, we ask three sets of questions to determine the suitability of integrated networks to deal with biodiversity redistributions, a common response to climate change. Dashed lines coming off intermediate steps indicate that they may or may not facilitate continued movement down the decision tree. While the focus here is on climate change impacts, land-use changes and other disturbances could also be integrated into the decision tree. 
(Rayfield et al., 2008). The long-term success of an integrated network approach therefore depends on responsible landscapescale management (Hansen and DeFries, 2007). Specifically, an area's capacity to serve as a dynamic conservation area in the future depends on sustainable landscape management by stakeholders after protection is lifted. The tempo of the ecological process(es) should also be considered, relative to the pace of implementing PAs or dynamic conservation areas. For example, in the context of biodiversity redistributions (Figure 2), some pelagic marine species' ranges are expanding at rates exceeding hundreds of kilometers per decade (Poloczanska et al., 2013), and therefore may benefit from temporary protection if it can be enacted faster that permanent PAs.

Another set of decisions relates to the logistics of implementation (Figure 2, Part 3). While specific logistical constraints, including management and transaction costs, and enforcement issues, are highly context-specific, our decision framework acknowledges that these all require careful consideration by diverse stakeholders. It will be important to clarify that dynamic conservation areas are intended to complement permanent PAs, rather than detract resources from them, because PA degradation, downsizing and degazettement (PADDD) is an ongoing threat to conservation success (Mascia and Pailler, 2011). However, in highly modified or fragmented landscapes, dynamic conservation may be the only available option to provide place-based protection that balances stakeholder interests with species or ecosystem conservation (Lawler, 2009; Kattwinkel et al., 2011).

Our focus in this perspective is on the biological processes underpinning the design of coupled networks of permanent PAs and dynamic conservation areas, but we acknowledge that implementing such networks will require a holistic consideration of other social, economic, and cultural factors. Indeed, the systematic conservation planning process aims to minimize societal costs while optimizing biodiversity, with more recent thinking emphasizing stakeholder engagement and the implementation process (McIntosh et al., 2017). In many ways, dynamic conservation is amenable to community-led conservation because it can be achieved by coalitions of private landowners or other stakeholders, akin to conservation in traditionally farmed landscapes (Fischer et al., 2012). Indeed, some precedent can be found in multi-tenure reserve networks that integrate temporary mechanisms and permanent PAs (Fitzsimons and Wescott, 2005). Future work on these networks will therefore benefit from interdisciplinary work that adopts a socio-ecological perspective.

Designing spatial networks with permanent and dynamic components will also benefit from supporting policy and legislation that recognizes the adaptive nature of dynamic conservation, and the need to implement them over faster timescales than traditional permanent PAs. Many policies, laws, and regulations do not include provisions for climate change, let alone quick dynamic actions, thus requiring revisions (Mawdsley et al., 2009; Mills et al., 2015). However, successful dynamic efforts reveal diverse approaches to implementation, including cooperation between NGOs and private landowners (Reynolds et al., 2017), and collaborations between scientists, managers, and industry partners (Hobday et al., 2010). Additionally, guiding documents that are a step in the right direction do exist. The most significant is the Strategic Plan for Biodiversity 2011-2020 adopted by parties to the Convention on Biological Diversity. Included in the Strategic Plan is Aichi Target 11; a commitment to protect 17 and $10 \%$ of terrestrial and marine systems, respectively, through the establishment of PAs or Other Effective Conservation Measures (OECMs). While PAs and OECMs emphasize long-term conservation objectives, Areas of Connectivity Conservation have been proposed as a complementary strategy that can take on more flexible tenures and may include temporary conservation areas (Worboys et al., 2016).

\section{CONCLUSIONS}

Ensuring biodiversity persistence under accelerating climate change requires agile conservation strategies that enable sustainable solutions. The integration of permanent PAs and dynamic conservation areas reflects a new type of flexible conservation strategy that, alongside alternative conservation actions such as restoration and translocation, could promote network persistence, facilitate redistributions, and protect transient ecosystems. Given the long-term process required for the designation and implementation of permanent PAs, dynamic management presents a novel mechanism for shortterm responsiveness to the urgency of climate impacts and uncertain ecosystem responses. This integrated approach will also require updated policies and legislation that explicitly incorporate climate change and opportunities for temporary protection into conservation planning, as well as monitoring and coordination across local, regional, and international boundaries. By diversifying the conservation portfolio to reflect opportunities and constraints of global environmental changes, there is the potential for improved use of conservation approaches to ensure timely and successful outcomes under climate change.

\section{AUTHOR CONTRIBUTIONS}

All authors conceived of the project. CD and IN-L led the writing, and all authors contributed to manuscript revision, and read and approved the submitted version.

\section{FUNDING}

This work was funded by the Canadian Institute of Ecology and Evolution through a working group grant to CD, IN-L, and M-JF.

\section{ACKNOWLEDGMENTS}

We gratefully acknowledge funding from the Canadian Institute of Ecology and Evolution for our working group held in 2016 "Canadian protected areas in a changing climate: A crossecosystem approach to designing effective networks of protected areas." This manuscript greatly benefited from comments by two reviewers and Dr. Laura Kehoe. 


\section{REFERENCES}

Alagador, D., Cerdeira, J. O., and Araújo, M. B. (2014). Shifting protected areas: scheduling spatial priorities under climate change. J. Appl. Ecol. 51, 703-713. doi: 10.1111/1365-2664.12230

Araújo, M. B., Alagador, D., Cabeza, M., Nogués-Bravo, D., and Thuiller, W. (2011). Climate change threatens European conservation areas. Ecol. Lett. 14, 484-492. doi: 10.1111/j.1461-0248.2011.01610.x

Armstrong, T. E., Gluck, M., Hooper, G., Mettam, I., Racey, G. D., and Rondeau, M. (2012). Caribou conservation and recovery in Ontario: development and implementation of the Caribou Conservation Plan. Rangifer 32, 145-157. doi: 10.7557/2.32.2.2266

Beckage, B., Gross, L. J., and Kauffman, S. (2011). The limits to prediction in ecological systems. Ecosphere 2, 1-12. doi: 10.1890/ES11-00211.1

Bengtsson, J., Angelstam, P., Elmqvist, T., Emanuelsson, U., Folke, C., Ihse, M., et al. (2003). Reserves, resilience and dynamic landscapes. Ambio 32, 389-396. doi: 10.1579/0044-7447-32.6.389

Bull, J. W., Suttle, K. B., Singh, N. J., and Milner-Gulland, E. J. (2013). Conservation when nothing stands still: moving targets and biodiversity offsets. Front. Ecol. Environ. 11, 203-210. doi: 10.1890/120020

Cumming, S. G., Burton, P. J., and Klinkenberg, B. (1996). Boreal mixedwood forests may have no "representative" areas: some implications for reserve design. Ecography 19, 162-180.

Daigle, R. M., Metaxas, A., Balbar, A., McGowan, J., Treml, E. A., Kuempel, C. D., et al. (2018). Operationalizing ecological connectivity in spatial conservation planning with Marxan Connect. bioRxiv [Preprint]. doi: 10.1101/ 315424

Environment Conservation Council (2000). Marine, Coastal and Estuarine Investigation Final Report. Environment Conservation Council, Melbourne.

Fischer, J., Hartel, T., and Kuemmerle, T. (2012). Conservation policy in traditional farming landscapes. Conserv. Lett. 5, 167-175. doi: 10.1111/j.1755-263X.2012.00227.x

Fitzsimons, J. A., and Wescott, G. (2005). History and attributes of selected Australian multi-tenure reserve networks. Aust. Geogr. 36, 75-93. doi: $10.1080 / 00049180500050904$

Fordham, D. A., Akçakaya, H. R., Araújo, M. B., Keith, D. A., and Brook, B, W. (2013). Tools for integrating range change, extinction risk, and climate change information into conservation management. Ecography 36, 956-964. doi: 10.1111/j.1600-0587.2013.00147.x

Fuller, R. A., McDonald-Madden, E., Wilson, K. A., Carwardine, J., Grantham, H. S., Watson, J. E., et al. (2010). Replacing underperforming protected areas achieves better conservation outcomes. Nature 466, 365-367. doi: 10.1038/nature09180

Game, E. T., Bode, M., McDonald-Madden, E., Grantham, H. S., and Possingham, H. P. (2009). Dynamic marine protected areas can improve the resilience of coral reef systems. Ecol. Lett. 12, 1336-1346. doi: 10.1111/j.1461-0248.2009.01384.x

Gerber, L. R., Mancha-Cisneros, M. D. M., O'Connor, M. I., and Selig, E. R. (2014). Climate change impacts on connectivity in the ocean: implications for conservation. Ecosphere 5, 1-18. doi: 10.1890/ES13-00336.1

Golet, G. H., Low, C., Avery, S., Andrews, K., McColl, C. J., Laney, R., et al. (2018). Using ricelands to provide temporary shorebird habitat during migration. Ecol. Appl. 28, 409-426. doi: 10.1002/eap.1658

Guichard, F., Levin, S. A., Hastings, A., and Siegel, D. (2004). Toward a dynamic metacommunity approach to marine reserve theory. Bioscience $54,1003-1011$. doi: 10.1641/0006-3568(2004)054[1003:TADMAT]2.0.CO;2

Hannah, L., Midgley, G., Andelman, S., Araújo, M., Hughes, G., Martinez-Meyer, E., et al. (2007). Protected area needs in a changing climate. Front. Ecol. Environ. 5, 131-138. doi: 10.1890/1540-9295(2007)5[131:PANIAC]2.0.CO;2

Hansen, A. J., and DeFries, R. (2007). Ecological mechanisms linking protected areas to surrounding lands. Ecol. Appl. 17, 974-988. doi: 10.1890/05-1098

Hill, J. K., Griffiths, H. M., and Thomas, C. D. (2011). Climate change and evolutionary adaptations at species' range margins. Annu. Rev. Entomol. 56, 143-159. doi: 10.1146/annurev-ento-120709-144746

Hobday, A. J., Hartog, J. R., Timmiss, T., and Fielding, J. (2010). Dynamic spatial zoning to manage southern bluefin tuna (Thunnus maccoyii) capture in a multi-species longline fishery. Fish. Oceanogr. 19, 243-253. doi: $10.1111 /$ j.1365-2419.2010.00540.x
Hughes, T. P., Kerry, J. T., Álvarez-Noriega, M., Álvarez-Romero, J. G., Anderson, K. D., Baird, A. H., et al. (2017). Global warming and recurrent mass bleaching of corals. Nature 543, 373-377. doi: 10.1038/nature21707

Hussey, N. E., Kessel, S. T., Aarestrup, K., Cooke, S. J., Cowley, P. D., Fisk, A. T., et al. (2015). Aquatic animal telemetry: a panoramic window into the underwater world. Science 348:1255642. doi: 10.1126/science.1255642

Johnson, C. A., Neave, E., Blukacz-Richards, A., Banks, S. N., and Quesnelle, P. E. (2017). Knowledge Assessment (Community and Scientific) to Inform the Identification of Critical Habitat for Peary Caribou, Rangifer Tarandus Pearyi, in the Canadian Arctic. Ottawa, ON: Environment and Climate Change Canada.

Jones, K. R., Watson, J. E., Possingham, H. P., and Klein, C. J. (2016). Incorporating climate change into spatial conservation prioritisation: a review. Biol. Conserv. 194, 121-130. doi: 10.1016/j.biocon.2015.12.008

Kattwinkel, M., Biedermann, R., and Kleyer, M. (2011). Temporary conservation for urban biodiversity. Biol. Conserv. 144, 2335-2343. doi: 10.1016/j.biocon.2011.06.012

Kays, R., Crofoot, M. C., Jetz, W., and Wikelski, M. (2015). Terrestrial animal tracking as an eye on life and planet. Science 348:aaa2478. doi: $10.1126 /$ science.aaa 2478

Keppel, G., Mokany, K., Wardell-Johnson, G., Phillips, B., Welbergen, J., and Reside, A. (2015). The capacity of refugia for conservation planning under climate change. Front. Ecol. Environ. 13, 106-112. doi: 10.1890/140055

Kininmonth, S., Drechsler, M., Johst, K., and Possingham, H. P. (2010). Metapopulation mean life time within complex networks. Mar. Ecol. Prog. Ser. 417, 139-149. doi: $10.3354 /$ meps08779

Knight, A. T., Cowling, R. M., and Campbell, B. M. (2006). An operational model for implementing conservation action. Conserv. Biol. 20, 408-419. doi: $10.1111 / j .1523-1739.2006 .00305 . x$

Lawler, J. J. (2009). Climate change adaptation strategies for resource management and conservation planning. Ann. N.Y. Acad. Sci. 1162, 79-98. doi: 10.1111/j.1749-6632.2009.04147.x

Lewison, R., Hobday, A. J., Maxwell, S., Hazen, E., Hartog, J. R., Dunn, D. C., et al. (2015). Dynamic ocean management: identifying the critical ingredients of dynamic approaches to ocean resource management. BioScience 65, 486-498. doi: 10.1093/biosci/biv018

Martensen, A. C., Saura, S., and Fortin, M. J. (2017). Spatio-temporal connectivity: assessing the amount of reachable habitat in dynamic landscapes. Methods Ecol. Evol. 8, 1253-1264. doi: 10.1111/2041-210X.12799

Mascia, M. B., and Pailler, S. (2011). Protected area downgrading, downsizing, and degazettement (PADDD) and its conservation implications. Conserv. Lett. 4, 9-20. doi: 10.1111/j.1755-263X.2010.00147.x

Mawdsley, J. R., O'Malley, R., and Ojima, D. S. (2009). A review of climatechange adaptation strategies for wildlife management and biodiversity conservation. Conserv. Biol. 23, 1080-1089. doi: 10.1111/j.1523-1739.2009. 01264.x

McIntosh, E. J., Pressey, R. L., Lloyd, S., Smith, R. J., and Grenyer, R. (2017). The impact of systematic conservation planning. Annu. Rev. Env. Resour. 42, 677-697. doi: 10.1146/annurev-environ-102016-060902

McLeod, E., Salm, R., Green, A., and Almany, J. (2009). Designing marine protected area networks to address the impacts of climate change. Front. Ecol. Environ. 7, 362-370. doi: 10.1890/070211

Mills, M., Weeks, R., Pressey, R. L., Gleason, M. G., Eisma-Osorio, R. L., Lombard, A. T., et al. (2015). Real-world progress in overcoming the challenges of adaptive spatial planning in marine protected areas. Biol. Conserv. 181, 54-63. doi: 10.1016/j.biocon.2014.10.028

Moilanen, A., Laitila, J., Vaahtoranta, T., Dicks, L. V., and Sutherland, W. J. (2014). Structured analysis of conservation strategies applied to temporary conservation. Biol. Conserv. 170, 188-197. doi: 10.1016/j.biocon.2014. 01.001

Mouquet, N., Lagadeuc, Y., Devictor, V., Doyen, L., Duputié, A., Eveillard, D., et al. (2015). Predictive ecology in a changing world. J. Appl. Ecol. 52, 1293-1310. doi: 10.1111/1365-2664.12482

Poloczanska, E. S., Brown, C. J., Sydeman, W. J., Kiessling, W., Schoeman, D. S., Moore, P. J., et al. (2013). Global imprint of climate change on marine life. Nat. Clim. Change 3, 919-925. doi: 10.1038/nclimate1958

Pressey, R. L., Cabeza, M., Watts, M. E., Cowling, R. M., and Wilson, K. A. (2007). Conservation planning in a changing world. Trends Ecol. Evol. 22, 583-592. doi: 10.1016/j.tree.2007.10.001 
Rayfield, B., James, P. M., Fall, A., and Fortin, M. J. (2008). Comparing static versus dynamic protected areas in the Quebec boreal forest. Biol. Conserv. 141, 438-449. doi: 10.1016/j.biocon.2007.10.013

Reynolds, M. D., Sullivan, B. L., Hallstein, E., Matsumoto, S., Kelling, S., Merrifield, M., et al. (2017). Dynamic conservation for migratory species. Sci. Adv. 3:e1700707. doi: 10.1126/sciadv.1700707

Runge, C. A., Martin, T. G., Possingham, H. P., Willis, S. G., and Fuller, R. A. (2014). Conserving mobile species. Front. Ecol. Environ 12, 395-402. doi: $10.1890 / 130237$

Scheffers, B. R., De Meester, L., Bridge, T. C., Hoffmann, A. A., Pandolfi, J. M., Corlett, R. T., et al. (2016). The broad footprint of climate change from genes to biomes to people. Science 354:aaf7671. doi: 10.1126/science.aaf7671

Schindler, D. E., and Hilborn, R. (2015). Prediction, precaution, and policy under global change. Science 347, 953-954. doi: 10.1126/science.1261824

Spiecker, B., Gouhier, T. C., and Guichard, F. (2016). Reciprocal feedbacks between spatial subsidies and reserve networks in coral reef meta-ecosystems. Ecol. Appl. 26, 264-278. doi: 10.1890/15-0478

Stapleton, S., LaRue, M., Lecomte, N., Atkinson, S., Garshelis, D., Porter, C., et al. (2014). Polar bears from space: assessing satellite imagery as a tool to track Arctic wildlife. PLoS ONE 9:e101513. doi: 10.1371/journal.pone.0101513

Stein, B. A., Staudt, A., Cross, M. S., Dubois, N. S., Enquist, C., Griffis, R., et al. (2013). Preparing for and managing change: climate adaptation for biodiversity and ecosystems. Front. Ecol. Environ. 11, 502-510. doi: 10.1890/120277

Thomas, C., and Gillingham, P. (2015). The performance of protected areas for biodiversity under climate change. Biol. J. Linn. Soc. 115, 718-730. doi: $10.1111 /$ bij. 12510

Thompson, P. L., Rayfield, B., and Gonzalez, A. (2016). Loss of habitat and connectivity erodes species diversity, ecosystem functioning, and stability in metacommunity networks. Ecography 40, 98-108. doi: 10.1111/ecog.02558

Tingley, M. W., Darling, E. S., and Wilcove, D. S. (2014). Fine-and coarse-filter conservation strategies in a time of climate change. Ann. N.Y. Acad. Sci. 1322, 92-109. doi: 10.1111/nyas.12484
Tommasi, D., Stock, C. A., Hobday, A. J., Methot, R., Kaplan, I. C., Eveson, J. P., et al. (2017). Managing living marine resources in a dynamic environment: the role of seasonal to decadal climate forecasts. Prog. Oceanogr. 152, 15-49. doi: 10.1016/j.pocean.2016.12.011

Urban, M. C., Bocedi, G., Hendry, A. P., Mihoub, J. B., Pe'er, G., Singer, A., et al. (2016). Improving the forecast for biodiversity under climate change. Science 353:aad8466. doi: 10.1126/science.aad8466

Watson, J. R., Kendall, B. E., Siegel, D. A., and Mitarai, S. (2012). Changing seascapes, stochastic connectivity, and marine metapopulation dynamics. Am. Nat. 180, 99-112. doi: 10.1086/665992

Whiteley, A. R., Fitzpatrick, S. W., Funk, W. C., and Tallmon, D. A. (2015). Genetic rescue to the rescue. Trends Ecol. Evol. 30, 42-49. doi: 10.1016/j.tree.2014.10.009

Worboys, G. L., Ament, R., Day, J. C., Lausche, B., Locke, H., McClure, M., et al. (Eds.). (2016). Advanced Draft, Area of Connectivity Conservation Guidelines IUCN. Gland.

Worboys, G. L., Francis, W. L., and Lockwood, M. (eds.). (2010). Connectivity Conservation Management: A Global Guide. London: Earthscan.

Conflict of Interest Statement: The authors declare that the research was conducted in the absence of any commercial or financial relationships that could be construed as a potential conflict of interest.

Copyright (c) 2019 D'Aloia, Naujokaitis-Lewis, Blackford, Chu, Curtis, Darling, Guichard, Leroux, Martensen, Rayfield, Sunday, Xuereb and Fortin. This is an open-access article distributed under the terms of the Creative Commons Attribution License (CC BY). The use, distribution or reproduction in other forums is permitted, provided the original author(s) and the copyright owner(s) are credited and that the original publication in this journal is cited, in accordance with accepted academic practice. No use, distribution or reproduction is permitted which does not comply with these terms. 